\title{
Work of the Unemployed
}

\section{An inquiry into individuals' experience of data usage in public services and possibilities for their agency}

\author{
Naja Holten Møller* \\ Department of Computer Science, \\ University of Copenhagen
}

\author{
Trine Rask Nielsen \\ Department of Computer Science, \\ University of Copenhagen
}

\author{
Christopher A. Le Dantec \\ School of Interactive Computing, \\ Georgia Institute of Technology
}

\begin{abstract}
Public services increasingly presume a new and more active role for individuals to play in datafied society. While design efforts increasingly attempt to include stakeholders, such attempts are often limited to professional perspectives. Little is known about how individuals who are subject to these solutions experience the increasing use of data about them. One example of public services is job placement. Taking design fiction as our approach, we invited individuals enrolled in job placement $(n=20)$ to reflect on the 'work of the unemployed', a fictive scenario where individuals make themselves eligible for support through sharing data. The fiction addresses power dynamics. The study shows how approaches, such as design fiction, are effective at including marginalized communities through changing the conditions for design. Showcasing the fictional outlook, and how the 'design experience' can be disempowering if not qualified through a deeper critique, the paper contributes to agendas on design justice.
\end{abstract}

\section{CCS CONCEPTS}

- Human-centered computing $\rightarrow$ Interaction design; Interaction design process and methods; Scenario-based design.

\section{KEYWORDS}

Public services, Inclusivity, Design fiction, Job placement, Algorithmic systems, Politics of design

\section{ACM Reference Format:}

Naja Holten Møller*, Trine Rask Nielsen, and Christopher A. Le Dantec. 2021. Work of the Unemployed: An inquiry into individuals' experience of data usage in public services and possibilities for their agency. In Designing Interactive Systems Conference 2021 (DIS '21), fune 28-fuly 02, 2021, Virtual Event, USA. ACM, New York, NY, USA, 11 pages. https://doi.org/10.1145/ 3461778.3462003

\section{INTRODUCTION}

Data about individuals are becoming a key concern for designers and scholars in relation to the redesign of public services. Recent scholarship has focused on issues of individual representation in the face of data commodification in government-citizen interaction $[12,14,41]$, and on the consequences of the platform economy

Permission to make digital or hard copies of all or part of this work for personal or classroom use is granted without fee provided that copies are not made or distributed for profit or commercial advantage and that copies bear this notice and the full citation on the first page. Copyrights for components of this work owned by others than ACM must be honored. Abstracting with credit is permitted. To copy otherwise, or republish, to post on servers or to redistribute to lists, requires prior specific permission and/or a fee. Request permissions from permissions@acm.org.

DIS '21, fune 28-fuly 02, 2021, Virtual Event, USA

(C) 2021 Association for Computing Machinery.

ACM ISBN 978-1-4503-8476-6/21/06 ..\$15.00

https://doi.org/10.1145/3461778.3462003 as the point of departure for social transformation more broadly [20]. Together, these trends introduce new forms of data in public services for bureaucratic decision-making, integrating across platforms designed for interaction with individuals and algorithms that handle the vast amount of public data generated across public services $[7,15,16]$.

Critically, the existing scholarship has only been able to bring analysis of new uses of algorithms in public services to bear after new forms of data use are designed and institutionalized - potentially invisibly - in the decision-making infrastructures that gatekeep access to public services [29]. Another limitation of prior studies is the attempt to include stakeholders that are often limited to professional perspectives with specialist knowledge of data $[30,40,47]$, paving the way for the argument we make in this paper: that speculative approaches, such as design fiction, can be an effective method for both identifying systemic consequences of new data-driven algorithmic systems and for including marginalized and minoritized perspectives in the design process. A critical motivation for this research then, is changing the conditions for design as outlined in emerging scholarship around design justice [9, 13]. The 'design experience' can be disempowering of individuals if not qualified through a deeper critique [20,21, 24]. Showcasing the potential of a fictional approach for including marginalized communities [8], the paper contributes to agendas on design justice $[9,13]$.

Public services are increasingly designed with the goal of selfservice that presumes a new and more active role for individuals to play, specifically in relation to data production [7]. Individuals no longer live with digital media and platforms, but in digital media and platforms; in other words, as Lupton has argued, people live digital lives [23]. Digital applications, platforms, and services are designed to support and urge people to self-track and monitor their lives by generating data about themselves [32]. In the pursuit of profit, commercial operations use new types of data collection and prediction, but so do governments, as they search for new ways to use data of individuals to promote their version of the public good [31].

As governments - and technology designers more broadly increasingly turn to new uses of data and data-based solutions, it is crucial that designers and scholars critically reflect on these changes, develop research artefacts to examine the consequences of them, and bring the perspective of the individual subjects of these solutions into the design process $[14,20,26]$. Taking inspiration from prior research on the dilemmas that arise from viewing data as a commodity [41, 48], we used design fiction to develop a more nuanced understanding of how unemployed individuals experience the use of data about them for job placement. This approach also examined the conceptual ramifications of understanding data as 
'individual' as opposed to 'relational' [31, 39]; thus, understanding data as something that may be commodified critically shapes how we should make individual experiences a resource for designing service provisions [41].

The design fiction of this paper is a possible, yet fictional scenario (following, [43, 45, 46]): an app for unemployed individuals 'work' that they have to perform by managing how data about their lives are used in order to make themselves eligible for support. The context of our fictional app is the Danish job placement apparatus. This system could be moving towards more datafied processes in how it handles unemployment across the country, with even more work placed on individuals as part of the enactment of self-service social programs. Taking fiction as our starting point $[5,8]$, we invited individuals enrolled in job placement $(n=20)$ to reflect on a scenario where they had to share personal data to make themselves eligible for government support. This data-for-eligibility scheme is based on current job placement services today; however, in the fiction we developed, we expanded the kinds of data used for decision-making to include social media data, GPS data, smartwatch data, health data, web search data, and data from the individual's use of streaming services.

The focus on social media data and GPS data in the fiction came from current public debate over isolated instances of using these kinds of data [1, 2]. For example, in 2017 an individual posted information that the municipal job placement system considered relevant to their case. The individual was asked to put more effort into improving her work ability instead of cooking at home and then posting about it on social media. The individual's social media account in this case was 'open' to anyone [1]. The question for us, is what happens once the use of these data becomes institutionalized and designed - potentially invisibly - into the decision-making infrastructures that gatekeep access to public services? The design fiction we present is thus a design faction [3] that passes as real, and almost factual in the context where it is deployed. In particular, we wanted to give individuals more agency over data sharing in the fictional scenario and also understand what accountability looks like from the individual's perspective.

In this study, we found that individuals had a detailed understanding of how they are currently required to make themselves accountable as part of job placement and how different kinds of data about them are used in this process. Meanwhile, it was surprising to us that the individuals in our study did not seem to view themselves as active participants in the production of data. This influenced how they perceived the possibilities for their agency in the fictive scenario where unemployed individuals could choose which data they wanted to share as a basis for negotiating their eligibility for social support. In this sense, our findings support prior studies pointing to data as relational [39, 41, 42], which we found is shaped through the situated interaction with caseworkers. Data usage, we find, is experienced by individuals as more or less reasonable in this context, but their assessment of reasonableness runs into gaps. The non-technical public understand agency as the power to take control of usage of data as distinct from power over the conditions and implications of individual impact [following 39] Accordingly, designers of public services need to be attentive to the limits of how individual agency can be exercised in conditions that allow it.

\section{DESIGNING FOR INCLUSIVE AND JUST DATA USAGE IN PUBLIC SERVICES}

Growing faith and interest in data spurred designers and scholars to ask new questions on large scale social issues and how we can think through inclusive and just design practices [13]. In public services, such systems are considered for preventing child abuse [37], keeping teens in foster care safe [4], and providing the needed support for individuals that struggle with unemployment [16]. Turning to data to address these issues, trades interventions that are focused on social process and rooted in interaction between a social worker, parole officer, or job placement coach for varying degrees of automation rooted in the commodification of data as interchangeable and uncontestable [41, 42, 44]. Further, it imposes a command-andcontrol metaphor not to the services that might be delivered, but to the individuals who are now governed by those services [15]. While differences exist across a global experience of data production and context $[18,36]$, the contextual factors of data production remain paramount even as they exist largely for the benefit of the algorithmic system [22].

No professional practice or sector seems to work unaffected by the implementation of algorithmic systems, but our focus is on government policymakers that have strongly anticipated and place their faith in new datafied public services. Here, informed decisions are an essential reason for the increasing power vested in algorithmic authority, assuming that public datasets are available in the first place $[9,17,29]$. Such changes often give a new and more active role for individuals. While design efforts attempt to include stakeholders, such attempts are often limited to professional perspectives.

The challenge of moving public service design into community settings where the values of consensus-driven design from the workplace origins comes in contact with more contentious realities makes it particular challenging to fulfill the ambition of inclusive and just design [12]. The datafied services that affect those subject to its regulation and imposition reconfigures the interpersonal relationships between official and subject [41]. It makes contesting errors and omission difficult if not impossible $[10,11]$ and it burdens the most marginalized with unaccountable forms of automated regulation and governance [15].

Related to the structural, large-scale incentives described by Zuboff [48], Seberger et al point to the critical difference between individuals' power to act on the use of data as different from the power over usage of data [39]. Attempts to enact the "power to control use of data considered as 'individual' could lead to frustration and perhaps even resignation as the limits of the capacity to act are discovered, they point out, and lead to digital resignation in practice" [39 p. 4]. Where Seberger et al focus on the individual experiences of data, Zuboff takes aim at the structural incentives for platform own-ers and how those incentives create risks for individual platform users in the context of the current social media ecosystems [48]. Together these perspectives paint a disheartening landscape where consolidated power through social surveillance feeds back into an individually disempowering relationship to data produced about the individual. As public services continue their neoliberal turn, the challenges to individual agency and system accountability are ever more present in public services as similar logics of accumulation, 
automation, and scalar efficiencies work against contextualized, human-centered approaches to service provision [14, 24].

The introduction of algorithmic systems in areas such as public services raises new concerns, including a divergence between how individuals subject to these systems view their own agency from how professionals providing the services view the agency of their clients. As scholars working in the area of public service design, we recognize the importance of creating opportunities for individuals to participate in the design process [12]. The urgency of this issue is increased by demonstrating that that algorithmic systems tend to hide, accelerate, and deepen unjust structures of society, all while maintaining a veil of neutrality [6,9]. For unemployed individuals, being able to engage with data about themselves, support persons may lend authority to their case in important ways when different kinds of data are rolled up for programmatic decisions [31]. Thinking through more just design, it is critical to understand how individual's experience their possibility for agency and accountability in relation to the public services' use of data about them. Thus, we turn our attention to how data about individuals as a basis for algorithmic public services is produced and creates an opening for new forms of agency and accountability.

\subsection{Data as New Forms of Agency and Accountability}

Individuals are becoming more aware of the many ways in which our data is being collected, used, stored, and reused for purposes other than those for which we originally intended [32, 38]. Individuals are, to a certain extent, okay with these uses - especially if it is to their own advantage - such as for individualized treatment, or if fellow citizens can benefit from the data. But individuals also feel that how exactly data is captured and stored, and who chooses how it might be used is out of their hands. The lack of transparency in how and why data about private citizens is collected by public services, and the impact that has on individual agency $[6,19]$, has often been mis-framed as issues of data privacy [38,39].

The basic assumption behind privacy mechanisms is that "data subjects make conscious, rational and autonomous choices about the processing and management of data about them" [39]. This assumption is under great pressure in today's algorithmic societies [48]. Even when it is simply data that originates from the services provided (the direct service interaction), it is already effectively impossible for individuals to contest and correct such data $[10,11]$ The very idea of privacy as an enabler of individual agency is unsound; furthermore, research continues to show that people have trouble understanding privacy policies, despite efforts to increase user awareness of the consequences of personal data collection [39].

In commercial contexts, privacy is meant as an assurance in the exchange of data for service: the consumer gets to use a service and in exchange they become data subjects that are used to improve the service, or repackaged and sold as data commodities. In the neoliberal imagination, this arrangement is tolerable because the consumer has some presumed choice in whether or not they use the service. However, in job placement and other social service arrangements, the exchange of data-for-service becomes coercive as there is no viable choice on whether to accept social support.
This shifts the accountability from the provider (accountable for data privacy and stewardship) back to the individual as the mode of exchange to gain access to service. Here, individuals do not formally have a 'work' relationship with the job placement service, but they are still subjected to regimes of control that dictate how they spend their time - for example attending regular meetings at the job center - and how they must share data about themselves to account for that $[16,31,33]$. The resulting datasets, amassed by municipalities and made available for emerging algorithmic systems, are the outcome of many hours of work by municipal caseworkers. However, the unemployed individuals increasingly contribute to this work as well [31].

From these prior studies, it is apparent how accountability and agency are intertwined in practice and reconfigure relationships. Some social groups benefit from these 'dataveillance' strategies, while others are disadvantaged or marginalized [6,9]. Data at work is already transgressing what is normally considered personal and what is considered work-related [25]. As data in public services shift from being mainly produced and used for informing decisions of individuals toward becoming large-scale data produced, managed, and used across many individuals and agencies, accountability shifts for individuals and for caseworkers. In job placement, caseworkers understand their limitations [29]. They describe their job as working with individuals, while supporting them to advocate for their perspective and provide relevant information on the law that apply in their case. Prior decisions are reconsidered by caseworkers as part of this process, knowing that rules shift and caseworkers do not all agree on how to apply them in practice [Ibid]. It raises questions on what the new forms of agency and accountability are that follows from a more active role for the individual, one that demands that they do another type of work, as providing data is increasingly articulated as a civic duty (as currently suggested by the EU [2]). How will it reconfigure interaction if the role of the caseworkers is merely to be the 'broker' of data about an individual in job placement? How do individuals experience their possibility for agency and accountability in such a near future algorithmic public services?

\section{A FICTIONAL APP: JOBNETTRACE}

To further explore the consequences of the issues raised above, we created a design fiction that aims to be provocative while at the same time familiar and recognizable. Following Auger, "in the domains where these fictions ply their wares and meet their audiences, it is preferable for the concept to pass as real," almost as a fact - a design faction [3]. Like others before us, we presented a design fiction 'research artefact' to understand how unemployed individuals experience the use of data about them by the public services [following 28].

The public sector increasingly follows a neoliberal logic similar to that of commercial operations, [20]. We are interested in dilemmas in relation to accountability and agency in public services. Thus, what are the kinds of accountability and agency that can be leveraged in the context of job placement if data of unemployed individuals are considered as individual property that can be traded with the public sector in return for support? 


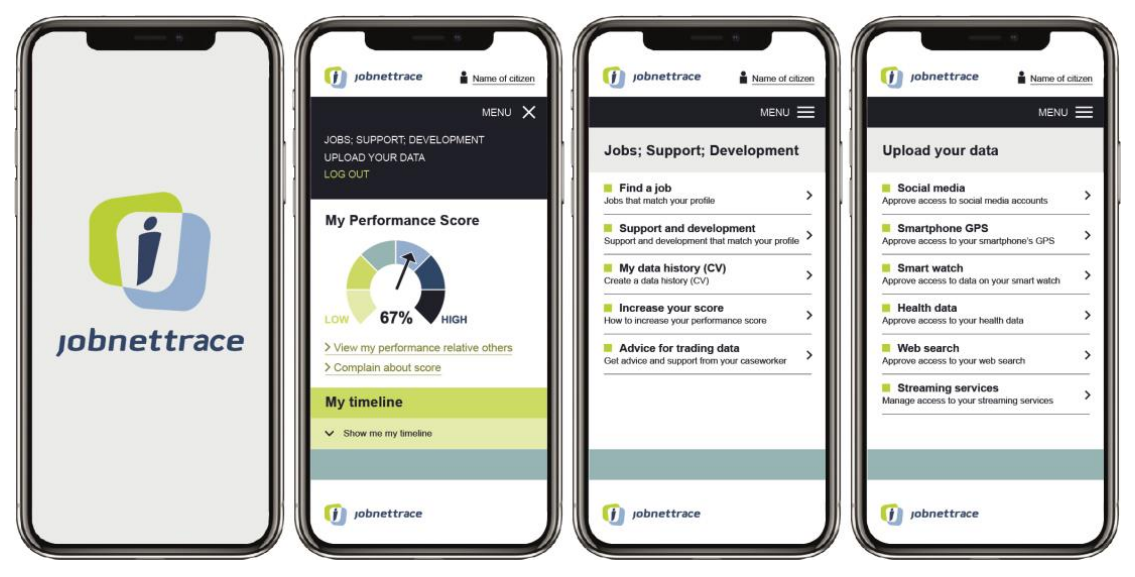

Figure 1: The fictive app jobnettrace

In our speculative scenario, Jobnet.dk is replaced by the fictional jobnettrace as the platform and app for individuals' interaction with caseworkers. Prior to the introduction of jobnettrace, the caseworkers focused both on the support and control of the job placement of individuals by making decisions on individual eligibility for job placement support. Unemployed citizens still have to meet legal criteria such as the 225-hour rule limiting unemployment benefits. The rule requires that citizens work at least 225 hours per year to earn the right to full financial support ${ }^{1}$.

Now imagine the new platform jobnettrace (Figure 1) a further development of jobnet.dk with self-tracking elements. On this platform, individuals can apply for particular services and job placement offers using the job center app. Instead of a caseworker making decisions on eligibility, support is earned as the unemployed individual uploads self-tracking data (e.g. smartphone, web search logs, smart watches, etc.). The data are assessed by an algorithm that makes decisions on eligibility. In this near-future speculative scenario, data gathering and the application for job placement is the 'work' of the unemployed individual, thus releasing more time for the caseworker to act as a support person.

The algorithm that we assume in the speculative scenario is similar to one already used for classifying data from different forms of tracking of employees' performance using data on social media, location, movement, etc. [27]. In jobnettrace, unemployed 'working' individuals similarly can provide their data from tracking of location, movement, etc. and in this way the app enables new forms of accountability and agency in job placement. The algorithm assesses if the uploaded data 1) corresponds to the value of support and development, or 2) data confirm the individual's job search performance in accordance with the legal criteria for eligibility. The algorithm also allows the individual to see their statistical performance score relative to others (Figure 1). Since the launch of jobnettrace, caseworkers have been acting as arbitrators, resolving the legality of decisions made by the algorithm on performance score. The caseworker still serves a critical role, ensuring citizens understand the legality of making a decision based on the performance score and their access to appeal, but also what may be the

\footnotetext{
${ }^{1}$ Law on Employment and Labour https://www.retsinformation.dk/eli/lta/2019/548
}

shortcoming of the algorithmic 'scoring' as caseworkers observe trends across individual's cases.

\section{METHOD}

The research artefact jobnettrace draws on empirical insights from a prior study that ethnographically examined caseworkers' and individuals' interactions in job placement [31]. The artefact itself falls within the category of design fiction that aims to establish a more inclusive practice that allow stakeholder perspectives to be represented, for example, in politically thorny areas that are often the focus of this genre [8,28]. In our case, the redesign of public services with data and algorithms makes it challenging to involve stakeholders with a legitimate interest in the shaping of job placement.

The research artefact we created aims to be recognizable to individuals in job placement (e.g. we use graphics and colors that are similar to the current system jobnet.dk). At the same time, we wanted the artefact to make concrete how mechanism for agency and accountability can be rebalanced through placing data about the individual at the center of our design fiction: jobnettrace (Figure 1). A caseworker will normally gatekeep the assembling of data for job placement. In the fictive artefact, the individual has more agency; however, this concept of agency also involves more work for the unemployed individual trying to assess how sharing data in jobnettrace will affect their performance score for accountability.

After having created the artefact (a 3 minute video presenting jobnettrace), we set up four online focus groups using Padlet as an interactive media for involving unemployed individuals. We wanted them to know that the artefact and scenario is fictive and not intended to ever be developed into a useable app. This was described in the introduction to the video presenting jobnettrace. Padlet allowed us to create a space for debate between the individuals in the focus groups while not demanding of them that they had to meet, participate at a specified time, or give up their anonymity within the group. The identities of all participants were kept anonymous in the final transcription and data analysis of the Padlet wall. The following instructions guided the debate in the online focus groups: 


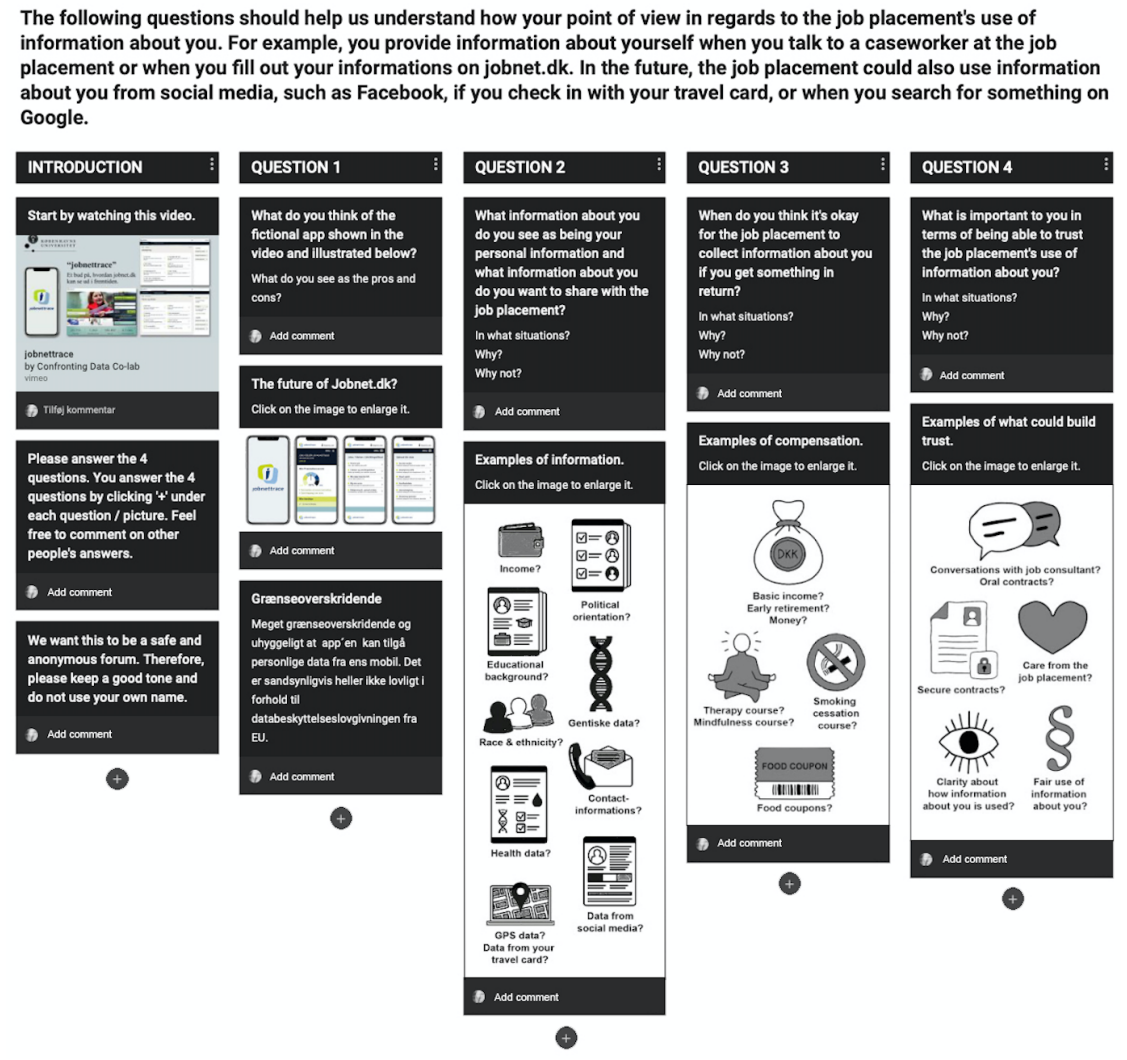

Figure 2: The interactive Padlet used for facilitating reflection in the four online focus groups.

- The focus group will answer and discuss four questions related to the topic posted in the information letter and sent out to participants via email.

- The questions on Padlet will be answered and discussed within a period of five weekdays.

- Participants will read, reflect, reply, and comment at times of their own choosing, but are expected to be regularly active on Padlet during this period of time (five days).

- Participants are expected to reply to each question posted in Padlet by the facilitator.

- Participants are encouraged to comment on each other's answers and discuss the questions with one another.

- Participants are expected to keep a respectful tone towards other participants.

A benefit of using a Padlet wall is the psychological and physical distance of the Internet with the potential to encourage group participation, especially for people who might otherwise not participate in a face-to-face focus group [35]. As Padlet allows people to participate anonymously, interaction through this media can reduce perhaps unequal power relations that might arise from visible differences such as e.g. gender, age, and ethnicity that would appear in a Facebook group. Furthermore, an asynchronous online focus group lets stakeholders read, reflect, and reply at times of their own choosing, which allows more time for careful consideration.
Finally, data collected online is written by the participants and thus increases the accuracy of the transcripts.

However, there are also limitations to Padlet compared to faceto-face focus groups. For example, it is difficult to engage with Padlet on a phone. We considered if this could be one obstacle for unemployed individuals with fewer resources that may also be using their phone as a computer. One other concern is that we cannot know for sure that all individuals engaged in the debate because we gave priority to the individuals anonymity. Instead, we considered the use of Padlet as an equivalent to the open and flexible research design that often characterize digital ethnography where reflections can be shaped and reshaped as a collaborative process throughout the research [34].

\subsection{Participant Recruitment and Sampling}

We turned to Facebook groups, as a strategy for ensuring diversity and inclusion of different types of people. In particular, we relied on four public Facebook groups with a combined membership of over 55,000 members. All Facebook groups are public and accessible for all to participate in sharing frustrations concerning the public sector, and some focus on job placement only. Thus, in Denmark, the context we write in, Facebook is considered a mainstream platform, as suggested by the number of members (55k). 

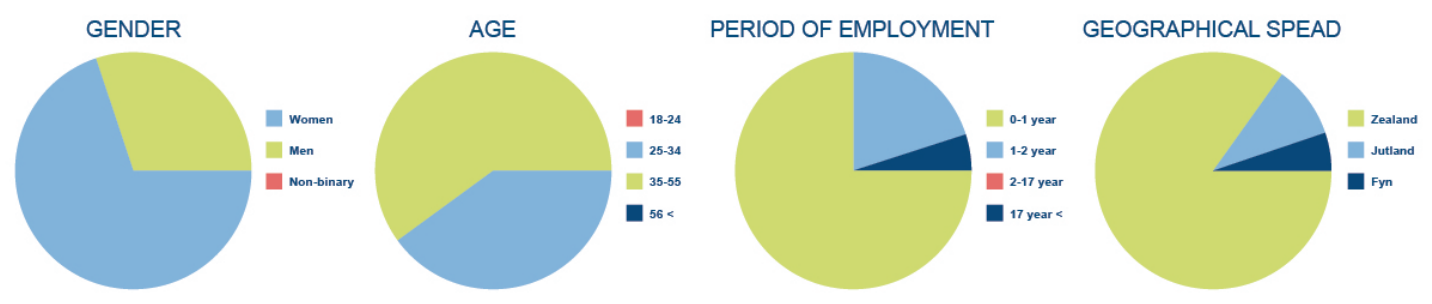

Figure 3: Participants in the study.

Our sampling strategy was decided in relation to our research question; the main criterion for sampling was 'years of unemployment', which we considered the main determinant for individuals' different experiences with how public services use data. In the sampling, we encouraged people with different ethnicities to participate in the study. Providing the option of identifying as female, male, or non-binary in the actual study was self-evident from our perspective; however, not a criterion that we considered to be determinant for how unemployed individuals experience the use of data about them.

In total, 20 individuals participated in the online Padlet focus groups, identifying as men $(n=6)$, women $(n=14)$, non-binary $(n=0)$. All of the participants were unemployed. 8 individuals were between 35 55 years old and 12 were between $25-34$ years old. All except 4 were living in the Capital Region of Denmark (Figure 3). The participants were mixed randomly into 4 online focus groups.

We followed current best practices and ethical regulations for protecting participant information (GDPR) and for facilitating informed consent. In return for their time spent, we decided to provide individuals with a $€ 20$ gift card, since a gift card is not considered as 'income' in the job placement regulation. It was important for us to avoid the threshold for what constitutes non-coercive remuneration for individuals participating in the study. All participants were informed about their right to withdraw from the focus group at any time.

The question that motivated this paper is what happens once the use of data about an individual becomes institutionalized and designed - potentially invisibly - into the decision-making infrastructures that gatekeep access to public services? Taking design fiction as our starting point, we wanted to invite unemployed individuals to reflect on uses of data about them for decision-making in job placement in algorithmic public services before they are institutionalized. Thus, we turn our attention to how unemployed individuals reacted to the fictive app jobnettrace: a scenario where the work of the unemployed is sharing their data as part of how they make themselves eligible to benefits and services in job placement.

\section{ANALYSIS}

Job placement is often experienced as being socially unjust. This is clear from social media where unemployed individuals form support groups, for example, "Victims of Job Placement" [in Danish
Jobcentrets Ofre ${ }^{2}$. Individuals point out that job placement is disempowering and these groups are used for sharing information on free legal advice. Others share their experiences of working around rules and penalties. Yet others share their stories of how they experience being 'part of the system'. Though, opinions expressed in these forums are not representative of all unemployed, and our sampling of unemployed individuals is not representative across this population, it shows the need for understanding and taking into account the experiences of unemployed individuals who have a legitimate interest in how emerging algorithmic systems are being developed.

\subsection{Individuals experience use of 'scores' as illegitimate and stressful}

jobnettrace speculates what the future could look like in algorithmic job placement by using data from social media, individuals' movement, etc. Although, there are some examples of how this kind of data about the individual has already been used for making decisions on eligibility in job placement, it is not a practice that has been integrated into the digital decision-making infrastructures. Aiming to be provocative, the fictive app shows a scenario where a new form of accountability is introduced when individuals are scored based on the data they decide to share using the app for job placement.

We learn from the responses to our fictive app jobnettrace that use of data for 'scoring' as a accountability mechanism is experienced as illegitimate and not supporting the unemployed. An important concern when being unemployed is the individual's ability to focus on searching for and getting a job, rather than spending time on meeting demands that are considered as administrative in nature. This is illustrated in the following excerpt from online focus group \#2 debating their impression of the fictional app (Q1 see Figure 2):

"The app seems like a terrifying example of surveillance and it is exclusively designed from the 'outside in' in order for the job centers to handle their tasks and develop those [individuals] who do not live up to the algorithm's standard [performance score]. If you want people to get closer to getting a job, this is not the way. Instead, the administrative burden should be taken off these individuals so that their energy can be used on job searching and not on placing demands

${ }^{2}$ https://www.facebook.com/groups/1490301027910427] 
of data capturing of no value. What is in it for the unemployed individual?"

"I find it problematic, and I would feel surveilled. Furthermore, I imagine that this measurement [performance score], which shows whether I live up to the requirements for job placement - that is, the thing where the arrow should preferably cross into the green area, showing that I am a good job seeker, will be (yet) another stress factor. Possible advantages [of the fictive app] could be getting faster notifications about job opening, or openings for further training, but since I have not yet experienced any concrete support of this kind from the job center, it works fine with an e-mail the way it is now."

"Agree that it could potentially be an advantage with a faster notification about a job opening, but I get these already from my LinkedIn app + lots of e-mails, so it would not really contribute anything new..."

"I already think that the job center is incredibly bad at listening, but really good at punishing. I would find such and app offensive. I started my path as an unemployed person full of optimism and now, I have lost a lot of faith in myself, due to the constant suspicion towards me, which is in the whole system. Most of all, I feel like saying: Fuck the Jobcenter."

"I can not really see any advantages. I do not need to be measured in relation to others."

“A score of ones 'success' would add yet another stress factor to being unemployed. It would not be motivating, as it is probably intended, because I would feel pressured to always keep an eye on my score. I miss an elaboration on what the score is based on?"

"I agree that especially being judged on how well you do as a job seeker would be a huge stress factor at a time when I already judge myself harshly, and feel judged every time I have to say out loud that I am unemployed. On top of all the rejections you get, it would be really uncomfortable to also have an app that tells you that you are not even good at being unemployed."

(Focus group 2)

What this transcript illustrates is how unemployed individuals find the use of a score as a mechanism for accountability to be stressful and even illegitimate. Even though the fictive app suggests that individuals themselves decide on what data they want to share (e.g. social media data, GPS data, smartwatch data, health data, web search data, and data from the individual's use of streaming services), one individual points out that it is still not clear what the score is based on. Several individuals report that they get a feeling of being surveilled and controlled. This was a recurring theme across the focus groups. Accountability in this case is at best considered an administrative feature. However, there were also individuals that were open to the use of data about them if the intentions for use were clear, as we shall see in the following.

\subsection{Data About the Individual is Neither a Commodity or Civic Duty}

The fictive app we designed (jobnettrace) suggests a scenario where data about an individual can be 'traded', speculating that in public services in the age of surveillance capitalism [41,48] data about the individual is a commodity as in other parts of our civic life. In jobnettrace it is an individual's decision if data can be used for job placement. Assuming that data about an individual are valuable, data may be traded in return for support. What we learn from the responses to this 'sharing' feature in the fictive app is that individuals are reluctant overall to trade data they see as personal in return for support, as illustrated in the following except: (Q2 see Figure 2):

"My social media and 'travel cards' are personal information. The job center does not know that at all. because... My employer in a given job should not have access to this [data]. Income and education [data], they are welcome to obtain in order to tailor a 'trajectory' for me".

"Yes, but no to surveillance."

"Income: Of course they need to know, because it's fair 'that I still receive support.

Educational background: Yes, then hopefully they can help me in my job search.

Health data: Yes, if I am entitled to sickness benefits. The rest: Absolutely not. Consider it surveillance."

"Can well understand there may be some [individuals] who do not come to the various job meetings and therefore it could be nice [for the job center] to track their GPS, to see if they had actually come. But it's anyway too much surveillance in my moss."

"Absolutely mysterious."

"I do not want to share my information from social media (except LinkedIn) as it does not concern them. I use my social media for my free time and not career. GPS [data] is not ok either. [Data on] ethnicity and genetic data may be ok, but it needs to be explained how the job center will use this data. Everything else is okay with me."

(Focus group 1)

Individuals in this focus group did not see the 'sharing' feature in jobnettrace as a possibility for more agency in job placement or accountability, it is clear from the above excerpt. One respondent in another focus group expressed concern about the risk of individuals feeling that they are being given full responsibility not only for data, but also for their unemployment and point to the risk of creating a stereotype 'ideal unemployed individual'. This could lead to a potential discriminatory and marginalizing of the unemployed individuals who are not willingly sharing data and therefore receive less support. Yet, not all individuals were unwilling or saw it as unlikely that they would share data. One respondent wrote (in response to Q3 - see Figure 2):

"Basically, I do not think it's okay for them [job center] to have personal information that is signed in 
good faith. That said, I'm probably quick to click accept and fill in the required information if that's what it takes for me to get $€$ paid. But I do not think it's okay. It is a bit like exploiting all of us naive individuals.”

(Focus group 2)

When considering sharing of data, consent and the opportunity to contest a legal decision is an important principle in public services. In the example here, an individual foresaw a 'quick to click' issue, one of the main reasons that data has become commodified in the first place and a clear example of how 'consent' is fundamentally broken as a mechanism for individual agency. Taking stock of the deep issues that already exist in data sharing, as known from the social media industry, it is clear how algorithmic public services can easily place 'work' on the unemployed individual. These individuals are depending on public benefits. It is not clear that an individual can take advantage of new forms of accountability and individual agency following from an understanding of data as individual property.

\subsection{Intention Matters for the Kinds of Data Individuals Share}

The caseworker is assumed to be a data 'broker' in the fictive app jobnettrace. Navigating job placement is already complicated. The legal regulations shaping this area are often changed. For the individual this means that the relationship with their caseworker is important for understanding how to make themselves accountable. In the fictive scenario, the caseworker was mainly assumed to explain to the individual how scores were being calculated and advised the individual in this regard. Asking unemployed individuals about what is important to them in terms of having trust in the use of data about them for job placement, the intention and 'human' in front of them matters, as illustrated in the following except: (Q4 see Figure 2):

"Trust in job placement can be increased if you as an unemployed is met with care and interest, as a human and individual, and not just a number in a row. It is, in fact, the most important thing that could be done differently [in job placement]. It will benefit the individual's motivation and probably also increase the sense of meaningfulness of the employees [caseworkers] at the job centers."

"Agree with the above comment that there is a need for care and interest for the individual, so that a greater relationship of trust in Jobnet as supportive and not just to control."

"I think that the jobcenter can be trustworthy only if the main aim is to support and not to control and judge. I was judged and offended often. These meetings sometimes led to stressful situations. While being unemployed for 11 months right after graduation I can say that mostly I was controlled. Until I got a trustworthy caseworker. A lot is defined by human interaction."

(Focus group 4)
Caseworkers can play an important role for building trust, these examples illustrate, when it comes to the use of data about an individual for job placement. The individuals talked about meaningfulness as a critical aspect on both sides, shaping job placement in important ways. Care for the individual is an important part of how caseworkers make any data useful in practice, this excerpt suggests. Accountability and individual agency are tied up with the experience of the caseworker as someone trustworthy that works together with the individual and takes an interest in them. At the other end of the spectrum, we find controlling measures where data is mainly described in terms of boxes that are used for data entries by the caseworker. One respondent wrote:

"The whole system is permeated by boxes that must be ticked off and that one has to be called to the carpet - without there being any real job guidance and help to move on."

(Focus group 2).

Ultimately, what comes across as important for these unemployed individuals is the sense of being treated as a human - by another human. jobnettrace was often talked about by these individuals as the existing system Jobnet.dk. The use of data about an individual for job placement is essentially based on the relationship with the caseworker in important ways. The responses from the individuals here suggest that there must be precise and direct information on the use of data for job placement, however, trust depended on the human relationship that caseworkers represented.

\section{DISCUSSION: MATERIALITIES OF POLICY IN PUBLIC SERVICE DESIGN}

This paper presents a design fiction, a fictive app jobnettrace as a way to take an inclusive approach to design with stakeholders in public services and gives voice to their experiences. Algorithmic public services are currently being developed [16, 29]. Job placement, like other kinds of public services, is increasingly becoming digitized and algorithmic. Such changes often presume a new and more active role for individuals to play. While participatory design efforts attempt to include stakeholders, such attempts are often limited to professional perspectives, in our case, management and caseworkers. Little is known about how individuals who are subject to these practices experience algorithmic services, which is our motivation for this paper following prior work on social justice in design [13]. From this perspective, unemployed individuals have a legitimate interest in the design of algorithmic public services [12]. Taking design fiction as our starting point $[8,21,28,44,45]$, we invited individuals enrolled into job placement $(n=20)$ to reflect on the 'work of the unemployed', a fictive scenario where individuals are making themselves eligible to support through sharing data.

Design interest in social justice literature engages questions of accountability and individual agency (e.g., $[4,13,14])$. Dombrowski et al. propose designing for accountability, a strategy to recognize and legitimatize an individual's experiences with social issues [13]. In the context of job placement, prior studies find that it is not unusual for individuals to experience job placement as marginalizing [31]. The increasing interest in using data for legal decision-making produced several examples in recent years of how the legal rules and norms for the use of data about an individual by public services 
is tested. For example, it became a point for public debate when an individual posted information that was considered relevant by the municipal job placement for decision-making in this individual's case [1]. The question for us in this paper is what happens once the use of these data about an individual become institutionalized and designed - potentially invisibly - into the decision-making infrastructures that gatekeep access to public services? The design fiction we present is thus what [3] would call a design faction that pass as real and almost factual in the context where it is put to work. In particular we wanted to give individuals more agency over data sharing in the fictional scenario and also understand what accountability looks like from the individual's perspective.

Here we look to other studies of how data have reconfigured public services and the relationships through which they are created. Shklovski et al. and others find that even when it is simply data that originates from the services provided (the direct service interaction), it is already effectively impossible for individuals to contest and correct such data [10,11, 41, 42, 44]. Seberger et al. distinguish between power to act on data and power over data usage. "Power over encodes within it inherent power imbalances and delimits the context within which power to can be exercised by individuals," they argue [39]. The very idea of privacy as a mechanism for individual agency is thus questionable from this perspective. Our study confirms this point. For example, one individual foresaw how it remains a challenge: when data are commodified, individuals tend to share more information than they intended to if it is necessary for gaining access to support. Taking stock of the deep issues that already exist in data sharing [48], it is clear how algorithmic public services can easily place not only 'work' on the unemployed individual, but also an ethically questionable decision for someone depending on public benefits.

Data at work is already transgressing what is normally considered as personal and what is considered as work-related, Mazmanian et al. finds; it creates an 'autonomy paradox' when individuals have to continuously navigate tensions between their interest in personal autonomy and their 'work' commitment [25]. In our case, the 'work of the unemployed' is comprised of individuals sharing data while navigating their interest in personal autonomy. In the case of unemployed individuals in need of support, what may seem to be individual agency in data exchange is actually a coercive exchange within the inherent hierarchy of the ever-growing market of data-dependent governance, our findings suggest. Data is a relational concept that is folded into the hierarchical interactions among caseworker and individual within the larger context of job placement.

A similar paradox exists in the early design work to understand the implications of algorithmic solutions, for example, public housing development projects [19]. Here we can see similar concerns rise where incidental data captured through the infrastructure that make the home 'smart' end up feeding regimes of control and regulation of individuals and families who depend on state provided or subsidized housing. In both cases - either public housing or the algorithmic provision of services - there is a gap and a scale problem that arises between where the work is done to operate these systems, where the benefits are accrued, and where the consequences are felt [Ibid]. In either case, individuals bookend this gap where residents are tasked with opening their lives to the experience of surveillance and voyeurism by the state so that potential gains in efficiency can be accrued at the macro scale of public services, meanwhile exposing those same individuals to uncontestable consequences of deviating from algorithmically enforced scores of compliance. This scenario means that as designers of algorithmic public services, we need to be less concerned with the materialities of data, sensing, and infrastructures and more concerned with the materialities of policy, regulation, and the state as it institutionalizes and encodes itself into digital infrastructures of bureaucratic decision-making. Accordingly, designers of public services need to pay attention to the limits of how individual agency can be exercised.

\section{CONCLUSION}

This paper contributes a design fiction: the research artefact jobnettrace designed to gain a better understanding of how unemployed individuals experience the use of data about them for job placement. The fictive app assumes a scenario where individuals are 'working' to make themselves accountable through sharing data, for example, social media data, GPS data, smartwatch data, health data, web search data, and data from the individual's use of streaming services. We invited individuals enrolled in job placement $(n=20)$ to reflect on this fictive app jobnettrace. Four online Padlet focus groups were set up for this purpose. All participants in the study were unemployed with different backgrounds.

We find that individuals did not perceive themselves as having agency in the use of data about them, even when they share and thus decide on what data can be used. The notion of agency cannot simply be assumed from the apparent power of making decisions on sharing data, following from an understanding of data as individual property and thus also responsibility. Our findings suggest that there is a gap and a scale problem that arises between where the work is done to operate these systems, where the benefits are accrued, and where the consequences are felt.

Secondly, we find that agency and accountability in data use are importantly shaped by the personal relationship between the individual and caseworker. Ultimately, what comes across as important for unemployed individuals in relation to the use of data for job placement is the sense of being treated as a human by another human. Unemployment individuals considered data sharing within a specific relationship and not as a commodity, nor a civic duty in our case.

What this scenario means for design of algorithmic public services, is that we need to be less concerned with the materialities of data, sensing, and infrastructures and more concerned with the materialities of policy, regulation, and the state as it institutionalizes and encodes itself into digital infrastructures of decision-making in public services.

\section{ACKNOWLEDGMENTS}

We thank all the individuals that were involved in the study for their engaged participation in the focus groups. We also extend our appreciation to the caseworkers and job centers that invited us to ethnographically study their practices, which has been the foundation for this work as part of the CompArt research project 2015-2018 supported by the Velux Foundations (award number 33295). Colleagues in the ECSCW community generously provided feedback 
on the first iteration of the fictional demo jobnettrace. Finally, we are indebted to Brit Winthereik and Irina Shklovski for discussing with us the nature of data - as well as Maria Menendez-Blanco, Thomas T Hildebrandt, Asbjørn Ammitzbøll Flügge, Geraldine Fitzpatrick, Marisa Cohn, Anette C. M. Petersen, and Tariq Andersen and the entire EcoKnow team that helped shape our ideas. This work has been supported by the Innovation Fund Denmark (award number 7050-00034A).

\section{REFERENCES}

[1] Agnes Andersen. 2017. Anita bagte julekager - nu straffer kmmunen hende [Anita was making Christmas cookies - now the municipality punishes her] Avisen.dk. Retrieved September 8, 2020 from https://www.avisen.dk/anita-bagtejulekager-nu-straffer-kommunen-hende_419586.aspx.

[2] Anna Artyushina. 2020. The EU is launching a market for personal data. Here's what that means for privacy. MIT Technology Review Retrieved 24.08.2020 https://www.technologyreview.com/2020/08/11/1006555/eudata-trust-trusts-project-privacy-policy-opinion/.

[3] James Auger. 2013. Speculative design: crafting the speculation. Digital Creativity, 24(1), 11-35.

[4] Karla Bardillo-Urquiola, Xinru Page and Pamela J. Wisniewski. 2019. Risk vs restriction: The tension between providing a sense of normalcy and keeping foster teens safe online. In Proceedings of the ACM Conference on Human Factors in Computing Systems (CHI), Article 267.

[5] Eric P. S. Baumer, Mark Blythe, and Theresa Jean Tanenbaum. 2020. Evaluating Design Fiction: The right tool for the job. In Proceedings of the ACM Conference on Designing Interactive Systems (DIS), 1901-1913.

[6] Ruha Benjamin. 2019. Race After Technology: Abolitionist Tools for the New Jim Code. Cambridge: Polity.

[7] Nikolaj Gandrup Borchorst and Susanne Bødker. 2011. "You probably shouldn’t give them too much information" - Supporting citizen-government collaboration. In Proceedings of the European Conference on Computer Supported Cooperative Work (ECSCW), 24-28.

[8] Lucas Colusso, Cynthia L. Bennett, Pari Gabriel, and Daniela K. Rosner. Design and diversity?: Speculation on what could go wrong. In Proceedings of the ACM Conference on Designing Interactive Systems (DIS), 1405-1413.

[9] Sasha Costanza-Chock. Design Justice. Community-led Practices to Build the Worlds we Need. The MIT Press.

[10] Christopher A Le Dantec and W Keith Edwards. 2008. The view from the trenches: Organization, power, and technology at two nonprofit homeless outreach centers. In Proceedings of the ACM Conference on Computer Supported Cooperative Work (CSCW) , 589-598.

[11] Christopher A Le Dantec and W Keith Edwards. 2010. Across boundaries of influence and accountability: The multiple scales of public sector information systems. ACM, 113-122.

[12] Christopher A. Le Dantec. 2016. Designing Publics. The MIT Press.

[13] Lynn Dombrowski, Ellie Harmon, and Sarah Fox. 2016. Social justice-oriented interaction design: Outlining key design strategies and commitments. In Proceedings of the ACM Conference on Designing Interactive Systems (DIS), 656-671.

[14] Andy Dow, Rob Comber, and John Vines. 2018. Between grassroots and the hierarchy: Lessons learned from the design of a public services directory. In Proceedings of the ACM Conference on Human Factors in Computing Systems (CHI), Article 442.

[15] Virginia Eubanks. 2018. Automating Inequality: How High-tech Tools Profile Police, and Punish the Poor. First edition. New York, NY: St. Martin's Press.

[16] Asbjørn Ammitzbøll Flügge, Thomas T. Hildebrandt, and Naja Holten Møller. 2021. Street-level algorithms and AI in bureaucratic decision-making: A caseworker perspective. PACM HCI 3(CSCW).

[17] Michael Hockenhull and Marisa Cohn. 2021. Speculative data work and dashboards: Designing alternative data visions. PACM HCI 3(CSCW), Article 264.

[18] Azra Ismail and Neha Kumar. 2018. Engaging solidarity in data collection practices for community health. Proceedings of the ACM Conference on Human-Computer Interaction (CHI), Article 76.

[19] Sandjar Kozubaev, Fernando Rochaix, Carl DiSalvo, and Christopher A. Le Dantec. 2019. Spaces and traces: Implications of smart technology in public housing. In Proceedings of the ACM Conference on Human Factors in Computing Systems (CHI), Article 439.

[20] Ann Light and Anna Seravalli. 2019. The breakdown of the municipality as caring platform: lessons for co-design and co-learning in the age of platform capitalism. CoDesign, 15 (3). 192-211.

[21] Ann Light, Gini Simpson, Lois Weaver, and Patrick G.T. Healey. 2009. Geezers turbines, fantasy personas: making the everyday into the future. In Proceedings of the ACM conference on Creativity and Cognition (C\&C '09), 39-48.

[22] Thomas Lodato and Carl DiSalvo. 2018. Institutional constraints: the forms and limits of participatory design in the public realm. In Proceedings of the ACM
Participatory Design Conference (PDC), Article 5.

[23] Deborah Lupton. 2016. The Quantified Self. Polity Press. https://doi.org/10.1111/ 1467-9566.12495.

[24] Caitlin Lustig, Katie Pine, Bonnie Nardi, Lilly Irani, Min Kyung Lee, Dawn Nafus, and Christian Sandvig. 2016. Algorithmic Authority: the Ethics, Politics, and Economics of Algorithms that Interpret, Decide, and Manage. In Proceedings of the ACM Conference Extended Abstracts on Human Factors in Computing Systems (CHI EA '16). Association for Computing Machinery, New York, NY, USA, 1057-1062.

[25] Melissa Mazmanian, Wanda J. Orlikowski, and JoAnne Yates. 2013. The autonomy paradox: The implications of mobile email devices for knowledge professionals. Organization Science 24(5):1337-1357.

[26] Maria Menendez-Blanco, Pernille Bjørn, and Antonella De Angeli. 2017. Fostering cooperative activism through critical design. In Proceedings of the ACM Conference on Computer Supported Cooperative Work (CSCW), 618-629.

[27] Shayan Mirjafari, Kizito Masaba, Ted Grover, Weichen Wang, Pino Audia, Andrew T. Campbell, Nitesh V. Chawla, Vedant Das Swain, Munmun De Choudhury, Anind K. Dey, Sidney K. D'Mello, Ge Gao, Julie M. Gregg, Krithika Jagannath, Kaifeng Jiang, Suwen Lin, Qiang Liu, Gloria Mark, Gonzalo J. Martinez, Stephen M. Mattingly, Edward Moskal, Raghu Mulukutla, Subigya Nepal, Kari Nies, Manikanta D. Reddy, Pablo Robles-Granda, Koustuv Saha, Anusha Sirigiri, and Aaron Striegel. 2019. Differentiating Higher and Lower Job Performers in the Workplace Using Mobile Sensing. In Proceedings of the ACM conference on Interact. Mob. Wearable Ubiquitous Technol. 3, 2, Article 37 (June 2019), 24 pages.

[28] Michael Muller, Jeffrey Bardzell, Eunjeong Cheon, Norman Makoto Su, Eric P.S. Baumer, Casey Fiesler, Ann Light, \& Mark Blythe. 2020. Understanding the past, present, and future of Design Fictions. In Extended Abstracts of the ACM Conference on Human Factors in Computing Systems (CHI EA), 1-8.

[29] Naja Holten Møller, Irina Shklovski, and Thomas T. Hildebrandt. 2020. Shifting Concepts of Value. Designing Algorithmic Decision-Support Systems for Public Services. Proceedings of the Nordic Conference on Human-Computer Interaction (NordiCHI).

[30] Naja Holten Møller, Claus Bossen, Kathleen H. Pine, Trine Rask Nielsen, and Gina Neff. 2020. Who does the work of data? ACM Interactions 27(3), 52-55.

[31] Naja Holten Møller, Geraldine Fitzpatrick, and Christopher A. Le Dantec. 2019. Assembling the Case: Citizens' Strategies for Exercising Authority and Personal Autonomy in Social Welfare. In Proceedings of the PACM HCI (GROUP), Article 244.

[32] Gina Neff and Dawn Nafus. 2016. Self-Tracking. The MIT Press.

[33] Anette C. M. Petersen, Lars Rune Christensen \& Thomas T. Hildebrandt. 2020. The role of discretion in the age of automation. Computer Supported Cooperative Work: An International Journal (JCSCW)

[34] Sarah Pink, Heather Horst, John Postill, Larissa Hjorth, Tania Lewis, and Jo A. Tacchi. 2016. Digital ethnography: Principles and Practices. Sage Publications Limited.

[35] Donna J. Reid and Fraser J.M. Reid. 2005. Online focus groups: An in-depth comparison of computer-mediated and conventional focus group discussions. International Journal of Market Research. 2005;47(2):131-162.

[36] Nithya Sambasivan, Shivani Kapania, Hannah Highfill, Diana Akrong, Praveen Kumar Paritosh, and Lora Mois Aroyo. 2021. "Everyone wants to do the model work, not the data work": Data Cascades in High-Stakes AI.

[37] Devansh Saxena, Karla Badillo-Urquiola, Pamela J Wisniewski, and Shion Guha. 2020. A Human-Centered Review of the Algorithms used within the U.S. Child Welfare System. In Proceedings of ACM Conference on Human Factors in Computing Systems (CHI), Article 102, 15 pages.

[38] Bart W. Schermer, Bart Custers, and Simone van der Hof. 2014. The crisis of consent: how stronger legal protection may lead to weaker consent in data protection. Ethics Inf Technol 16, 171-182.

[39] John S. Seberger, Marissel Llavore, Nicholas Nye Want, Irina Shklovski, and Sameer Patil. 2021. Empowering Resignation. There's an app for that. In Proceedings of ACM Conference on Human Factors in Computing Systems (CHI).

[40] Cathrine Seidelin, Yvonne Dittrich, and Erik Grönvall. 2020. Co-designing Data Experiments: Domain Experts' Exploration and Experimentation with selfselected Data Sources. Proceedings of the 11th Nordic Conference on HumanComputer Interaction (NordiCHI), Article 20.

[41] Irina Shklovski, Janet Vertesi, Emily Troshynski, and Paul Dourish. 2009. The commodification of location: dynamics of power in location-based systems. In Proceedings of the ACM conference on Ubiquitous computing. Association for Computing Machinery, New York, NY, USA, 11-20.

[42] Irina Shklovski, Emily Troshynski, and Paul Dourish. 2015. Mobile technologies and spatiotemporal configurations of institutional practice. Journal of the Association for Information Science and Technology, 66(10), 2098-2115.

[43] Marie Louise Juul Søndergaard and Lone Kofoed Hansen. 2018. Intimate futures: Staying with the trouble of digital personal assistants through design fiction. In Proceedings of the ACM Conference on Designing Interactive Systems (DIS), 869-880. 
[44] Emily Troshynski, Charlotte P. Lee, and Paul Dourish. 2008. Accountabilities of presence: Reframing location-based systems. In Proceedings of the ACM Conference on Human Factors in Computing Systems (CHI), 487-496.

[45] Richmond Y. Wong, Deirdre K. Mulligan. 2016. When a product is still fictional: Anticipating and speculating futures through concept videos. In Proceedings of the ACM Conference on Designing Interactive Systems (DIS), 121-133.

[46] Richmond Y. Wong, Deirdre K. Mulligan, Ellen Van Wyk, James Pierce, and John Chuang. 2017. Eliciting values reflections by engaging privacy futures using design workbooks. PACM HCI 1(CSCW), Article 111.

[47] Annika Wolff, Antti Knutas, Victoria Palacin, Cathrine Seidelin, Peter Kun, and Ingrid Mulder. 2019. Civic data literacies. In Proceedings of the International Conference on Communities and Technologies (C\&T), 306-309.

[48] Shoshana Zuboff. 2019. The Age of Surveillance Capitalism: The Fight for a Human Future at the New Frontier of Power. New York: Public Affairs. 